\section{Endoscopic submucosal dissection for venous lake in the submucosa of the transverse colon}

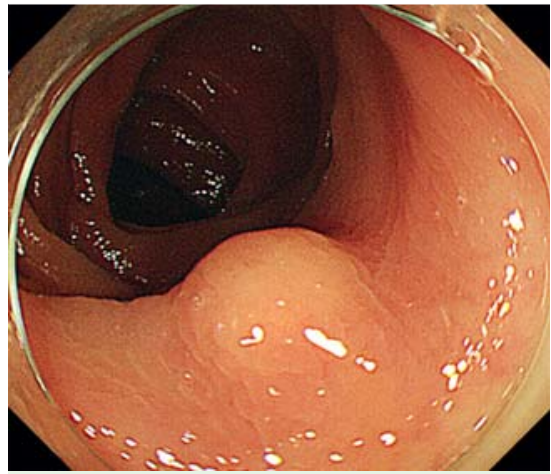

Fig. 1 Colonoscopy in a 51-year-old man reveals a slightly elevated lesion and normal yellowish mucosa in the transverse colon.

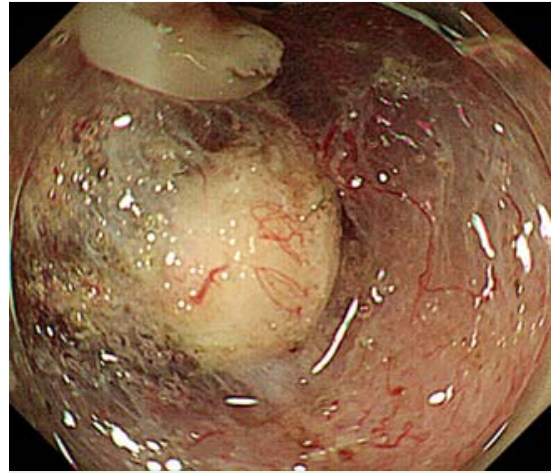

Fig. 2 On direct observation of the submucosal layer during endoscopic submucosal dissection, the lesion appears as a 5-mm spheroidal white mass.

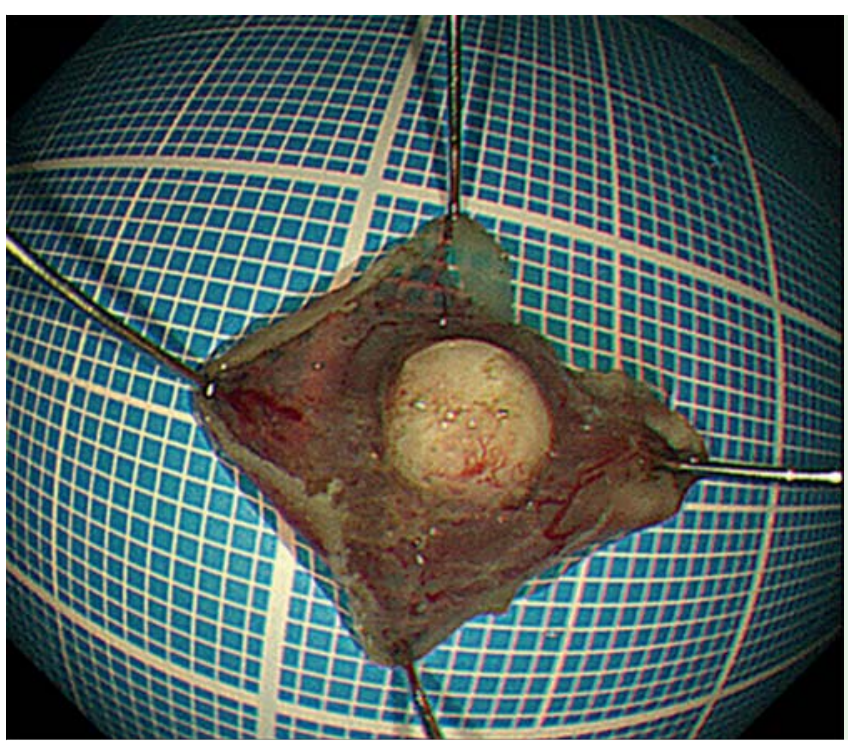

Fig. 3 There is a spheroidal white mass in the center of the specimen obtained from endoscopic submucosal dissection.

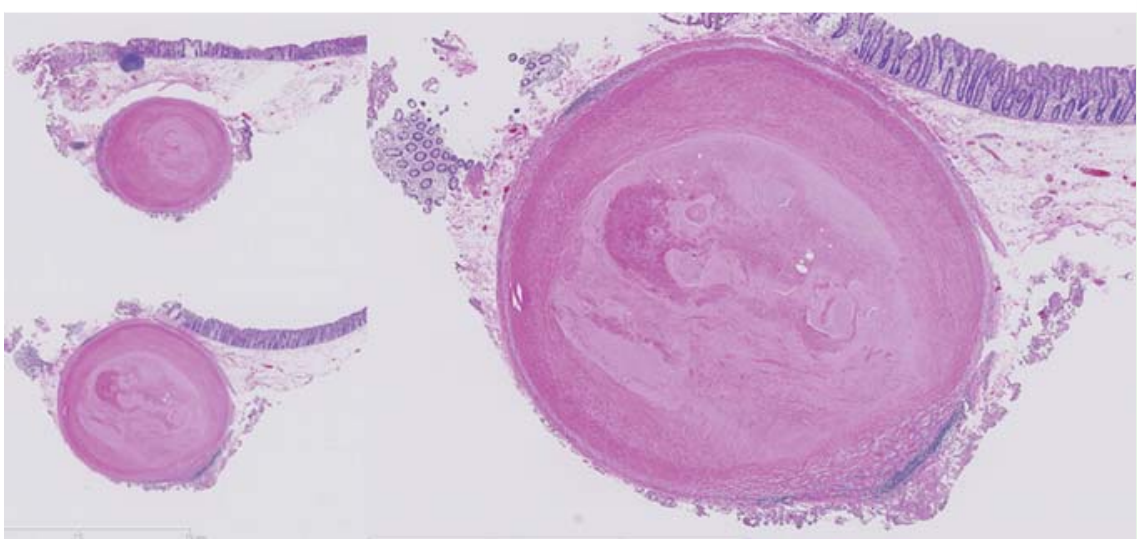

Fig. 4 Examination of the completely resected specimen reveals a 5-mm venous lake with thrombus, organized vasculature, and no neoplastic tissue.
Submucosal tumors of the transverse colon that are found incidentally during screening colonoscopy are rare. It is possible for a tiny hypoechoic mass detected in the submucosa of the colorectum by endoscopic ultrasonography (EUS) to be a neuroendocrine tumor (NET).

A 51-year-old man was referred to our department for examination of a submucosal lesion in the transverse colon. Colonoscopy revealed a slightly elevated lesion and normal yellowish mucosa ( $\bullet$ Fig. 1 ). On EUS, the lesion was a 5-mm hypoechoic uniform mass with a regular margin in the submucosal layer. Because a diagnosis of NET could not be ruled out, we performed endoscopic submucosal dissection (ESD) after obtaining written informed consent from the patient. Recent studies have reported that ESD is efficacious for submucosal tumors that have not spread beyond the submucosa because the dissection line during ESD is precisely determined under direct vision $[1,2]$.

First, to elevate the tumor, we injected sodium hyaluronate into the submucosa. After lifting the mucosa, we used a Flush Knife BT (DK2618JB; Fujifilm, Tokyo, Japan) to make a hemicircumferential mucosal incision around the tumor. Following the mucosal incision, we dissected the submucosa with a knife. Direct observation of the submucosal layer during ESD showed the lesion to be an approximately 5-mm spheroidal white mass ( $\bullet$ Fig. 2 , - Fig. 3; Video 1). The lesion was resected endoscopically en bloc. No major adverse events occurred. Histopathological examination revealed a venous lake with thrombus, organized vasculature, and no neoplastic tissue ( $\bullet$ Fig.4).

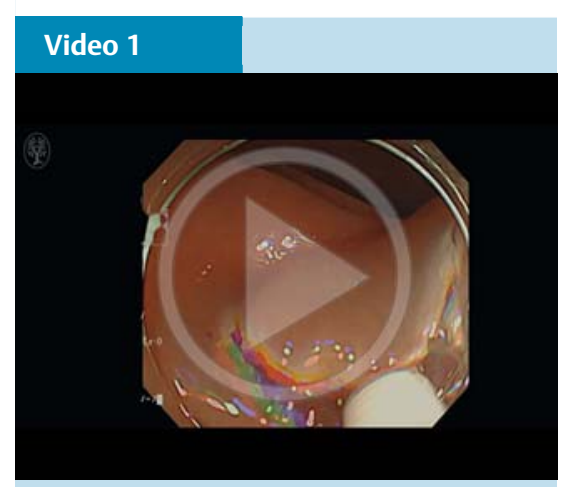

Endoscopic submucosal dissection of a venous lake in the submucosa of the transverse colon. 
Venous lake is rare in the digestive tract but is commonly seen by dermatologists on the lips or auricles. Histologically, a venous lake consists of dilated veins or venules filled with erythrocytes and lined by a single layer of flattened endothelial cells and a thin wall of fibrous tissue [35]. In this patient, the lesion was lined by a single layer of flattened endothelial cells and a wall of fibrous tissue, but the veins or venules had changed into thrombus with organized vasculature. To the best of our knowledge, this is the first report to describe a case of venous lake treated by ESD.

Endoscopy_UCTN_Code_CCL_1AD_2AF

Competing interests: None
Hideaki Harada', Satoshi Suehiro', Takanori Shimizu', Emi Ohta², Yasushi Katsuyama', Kenji Hayasaka ${ }^{1}$

${ }^{1}$ Department of Gastroenterology and Surgery, New Tokyo Hospital, Chiba, Japan

2 Department of Surgery, New Tokyo Hospital, Chiba, Japan

\section{References}

1 Lee DS, Jeon SW, Park SY et al. The feasibility of endoscopic submucosal dissection for rectal carcinoid tumors: comparison with endoscopic mucosal resection. Endoscopy 2010; 42: 647-651

2 Yamaguchi $\mathrm{N}$, Isomoto $\mathrm{H}$, Nishiyama $\mathrm{H}$ et al. Endoscopic submucosal dissection for rectal carcinoid tumors. Surg Endosc 2010; 24: 504-508

3 Bean WB, Walsh JR. Venous lakes. AMA Arch Derm 1956; 74: 459-463

4 Alcalay J, Sandbank M. The ultrastructure of cutaneous venous lakes. Int J Dermatol 1987; 26: 645-646

5 Neumann RA, Knobler RM. Venous lakes (Bean-Walsh) of the lips - treatment experience with the argon laser and 18 months follow-up. Clin Exp Dermatol 1990; 15: $115-118$
Bibliography

Dol http://dx.doi.org/ 10.1055/s-0034-1393141

Endoscopy 2015; 47: E538-E539

(C) Georg Thieme Verlag KG

Stuttgart · New York

ISSN 0013-726X

Corresponding author Hideaki Harada, MD

Department of Gastroenterology New Tokyo Hospital

1271 Wanagaya

Matsudo Chiba

Japan

Fax: +81-47-392-8718

nerimaendo@hotmail.co.jp 